\title{
AS IDENTIDADES CULTURAIS NA CONTEMPORANEIDADE. Dilemas e perspectivas em uma conjuntura pós-moderna*
}

\section{Ednaldo Aparecido Ribeiro}

Professor de Sociologia do Centro Federal de Educação Tecnológica - Cornélio Procópio; Aluno do Curso de Especialização em Sociologia e Sociologia da Educação da Universidade Estadual de Londrina.

Este artigo apresenta uma discussão sobre a definição das identidades culturais diante de uma conjuntura pós-moderna, marcada sobretudo por fenômenos como a mundialização econômica e a diluição das barreiras entre as nações. Trata-se de uma leitura sobre algumas posições teóricas contemporâneas das ciências sociais, em especial da antropologia, sobre os elementos e processos constitutivos das identidades em um contexto de transformação social acelerada.

Palavras-chave: pós-modernidade; identidades culturais; antropologia.

\section{INTRODUÇÃO}

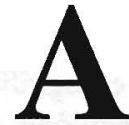
lgumas palavras parecem ter o dom sobrenatural (perdoem tamanho fetichismo) de dizer tudo e nada, ao mesmo tempo. Tal fenômeno tornou-se constante nos dias de hoje, em que palavras como globalização, pós-modernidade, mundialização, se tornaram algo naturalmente pronunciado por habitantes de favelas do Rio de Janeiro e homens de negócios de Wall Street, em Nova York. Lançados a todos os cantos, através dos meios de comunicação de massa, esses termos assumem o conteúdo ideológico de cada um dos agentes que os toma como discurso, o que acaba por torná-los palavras inócuas, sem significado algum.

Abandonando o fetichismo das palavras, esta imprecisão ou esta falta de sentido se deve a uma dificuldade atual de atribuirmos sentidos claros à nossa própria existência, tanto individual quanto coletiva. Vivemos em um mundo que se transforma de uma forma muito rápida. Tudo nos escapa. Tudo nos contém. Estamos ao mesmo tempo em toda parte, através das maravilhas da informática, e em lugar nenhum, em um isolamento crescente.

Somos, como diria uma campanha publicitária, cidadãos do mundo, e como tais não podemos nos prender a particularismos em um mundo integrado e sem fronteiras.
O que está em xeque na atualidade é a construção e a manutenção do que na antropologia convencionou-se chamar de identidade cultural, ou seja, um conjunto de sentidos construídos coletivamente que distinguem o eu do outro e pautam as relações entre estes dois níveis.

Toda construção de identidade, inclusive as individuais estudadas pela psicologia, partem do reconhecimento das semelhanças e das diferenças. Sou $e u$ na medida que reconheço no outro algo diferente de mim. Pertenço a determinado grupo à medida que reconheço em seus membros semelhanças. Em um mundo que, ao menos aparentemente, aboliu a diferença, temos uma profunda crise neste processo.

O objetivo deste texto é, à luz de alguns trabalhos recentes, discutir esta situação contemporânea de uma forma crítica, na tentativa de afastar tanto as apressadas teses da unificação cultural mundial quanto as românticas esperanças do isolamento total.

Tendo este objetivo, é interessante, ainda nesta introdução, definir o que entendemos por esta situação contemporânea que aqui chamaremos de pós-modernidade.

Marc Augé, antropólogo francês, em entrevista concedida a Paula Miraglia em 1997, faz uma critica à tradução brasileira de seu trabalho Não-lugares. Introdução a uma antropologia da supermodernidade, especificamente dirigindo-se à conversão do termo surmodernité (sobremodernidade) em supermodernidade. Justifica esta crítica com a

* O texto foi originalmente apresentado para avaliação à disciplina Cultura e Sociedade, ministrada pela professora Kimiye Tommasino, no curso de Especialização em Sociologia e Sociologia da Educação, da UEL, em 1999.

Rev. Mediações, Londrina, v. 4, n. 1, p. 7-13, jan./jun. 1999 
explicação sobre o que realmente pretendeu definir com tal vocábulo, ou seja, o processo de aceleração e potencialização de todas as tendências centrais do que convencionou-se chamar de modernidade e que teve seu grande início com as revoluções industriais européias e com a organização da sociedade na forma capitalista de produção. (AUGÉ, 1998)

Como identificou Karl Marx em sua obra maior, $O$ capital, com a expropriação dos meios de produção dos trabalhadores artesãos e dos camponeses estabeleceram-se as bases para o estabelecimento de um tipo de organização social em que a produção e a circulação de mercadorias se destacam como elemento estrutural. (MARX, 1991)

Entretanto, devemos ter em mente que estas transformações que se operaram nos últimos séculos não disseram respeito apenas a este nível econômico. Max Weber, em seus estudos sobre a modernidade, destaca a racionalização como categoria central de entendimento do contexto modernista. Com a dissolução dos espaços de valorização da tradição, dos laços sanguíneos e étnicos, laços de sociabilidade marcadamente anteriores ao período moderno, surge uma nova forma de entendimento sobre o mundo, pautada por uma dessacralização, ou como prefere Weber, pelo desencantamento. (WEBER, 1996)

Quando Marc Augé se refere à uma surmodernité, devemos ter em mente o processo atual de aceleração de todas estas características que marcam a sociedade capitalista desde o seu início, do nível econômico ao cultural. De fato, o capitalismo sempre foi globalizante, o que verificamos agora é que este processo atingiu níveis extraordinários de aceleração e potencialização. Trata-se de uma overmodernidade, marcada pela figura do excesso. (AUGÉ, 1994, p.32)

Diante desta surmodernité, acelerada e pontilhada por excessos, as ciências sociais, e sobretudo a antropologia, se colocam diante de problemas novos que exigem uma complexificação maior nas explicações propostas.

\section{POR UMA ANTROPOLOGIA MODERNA}

Pensando o contexto globalizado, MARCUS (1991) ressalta que o grande dilema da etnografia moderna é entender a formação das identidades culturais diante de uma tensão entre um processo de integração global e a reafirmação das autonomias locais.

Para este autor, um caminho que se tem mostrado muito fecundo é o que entende esta tensão como sendo movida por duas forças, resistência e acomodação, onde as identidades são formadas dentro de um quadro de constante negação e assimilação, definidos em negociações que se dão tanto no nível local quanto no mundial. (MARCUS, 1991, p.202)

Cada grupo cultural, ao inserir-se no processo de unificação em curso na atualidade, assimila certos traços uniformizantes, porém resistindo fortemente a outros. Até mesmo os traços aceitos passam por uma mutação interna que os transfigura e os torna peculiares à cultura nativa.
Para entender esses mecanismos de incorporação global e afirmação de particularismos, Marcus defende que seja realizada uma revisão teórico-metodológica por parte da antropologia, chegando a definir alguns requisitos que devem ser observados em etnografias que pretendam dar conta deste complexo de relações novas onde as identidades são definidas.

Tal revisão deveria dar-se em dois aspectos cruciais da investigação: a definição do observado e a do observador.

No que diz respeito ao primeiro ponto, este autor aponta que, devido às grandes transformações em curso na contemporaneidade, o entendimento acerca do observado, formulado pela etnografia tradicional, já não pode ser utilizado de forma eficaz.

Destaca que é necessário problematizar os principais critérios de definição das identidades dos observados: o espaço e o tempo.

O conceito de comunidade, antes válido para determinar a identidade de um grupo cultural, na medida em que todos os seus elementos constituintes estavam presentes em um limitado espaço geográfico, já não tem poder explicativo algum. As identidades no mundo pós-moderno já não respeitam barreiras terrestres, mas se pulverizam pela imensidão de um mundo em crescente integração, uma "identidade multilocalizada e dispersa". (idem, p.205)

O espaço, diante da pós-modernidade, deve ser repensado no que diz respeito à sua viabilidade como conceito antropológico, utilizado como elemento definidor de identidades culturais.

A problematização do tempo, porém, deve ser elaborada mediante uma crítica do historicismo empregado pela antropologia tradicional. Marcus defende uma retomada da noção de presente etnográfico, porém não nos moldes do funcionalismo clássico.

Este novo interesse pelo presente etnográfico tem como marca principal uma valorização da memória, ou seja, dos depoimentos individuais, que podem dizer muito mais sobre como as identidades são construídas, se comparadas com as análises históricas, que se prendem também à noção de comunidade.

Através do estudo das autobiografias torna-se possível captar um passado que se faz presente e que, filtrado pelo crivo da identidade individual, comporta um conjunto de elementos que podem explicar como se construiu ou como se mantém uma nova identidade localizada no centro da tensão entre o global e o local. (idem, p.205-207)

No entanto, a principal ruptura apontada por este autor como imprescindível para a fundação de uma etnografia atual refere-se ao conceito de estrutura. Esta ruptura é fruto de uma constatação: a falência do princípio da estrutura para a análise de uma realidade extremamente complexificada.

Procurar adequar a realidade pós-moderna dentro de modelos explicativos ou códigos rígidos de comportamento e ação é algo que não pode ser defendido como expediente de pesquisa no mundo contemporâneo.

Uma das alternativas visualizadas é a da polifonia, ou seja, entender os comportamentos sociais diversos, como vozes dentro de um diálogo constante na definição das identidades culturais. (idem, p.207) 
A análise das vozes comporta as duas outras revisões apontadas acima, uma vez que estas não se prendem à dimensão espacial e, muito menos, ao tempo histórico. A tarefa de uma etnografia polifônica é entender e dar sentido a um emaranhado de discursos caóticos, mas que, no entanto, é a base para a construção dos diversos particularismos culturais.

Com relação à redefinição do observador, Marcus destaca principalmente a necessidade de fundar uma etnografia dialógica, onde ao menos duas vozes estejam presentes: a do observador e a do observado.

Nada mais lógico que, em um contexto onde o observado é constantemente transformado pela rede de interações internacionais, os instrumentais de análise também se transformem. Entretanto, isto só é possível na medida em que se estabeleça uma relação onde o diálogo seja o elemento fundamental da pesquisa.

Deixar o nativo falar (sem que a antropologia abdique de seu trabalho científico, como adverte Augé) é algo essencial para que o investigador identifique os limites de seu método e possa, em tempo hábil, fazer as alterações necessárias.

Igualmente necessário para a fundação de uma etnografia do mundo globalizado é a bifocalidade. Muito já se refletiu sobre os impactos da observação e do contato do antropólogo nas comunidades em que realiza a pesquisa. $\mathrm{Na}$ atualidade a situação é ainda mais complexa e requer um esforço cada vez maior por parte do investigador.

Em um mundo sem fronteiras, cada vez mais a antropologia deixa de ser a ciência que estuda as populações exóticas e volta-se para o estudo do próximo. (MONTERO, 1991, p.117-120) A quebra das fronteiras entre as nações torna o mundo pequeno e nos coloca dentro de uma aldeia global onde o exótico se torna familiar.

Nesses termos, os impactos que a investigação produz devem ser agora aferidos com um duplo olhar, que identifica as conseqüências tanto para a vida do observado quanto para a do observador. Trata-se de rever o posicionamento do pesquisador diante de um objeto que, de tão próximo, coloca em crise a garantia da objetividade de que a ciência gozava. (idem, p.104-105)

Com esses pontos elencados, Marcus, através do que chama de "uso construtivo da desconstrução na etnografia modernista", pretende apontar a necessidade de uma profunda revisão nas bases de interpretação do mundo moderno, que apresenta como principal desafio o entendimento sobre como as identidades se constroem e se mantêm entre dois pólos em constante interação: o universal e o particular.

\section{AS IDENTIDADES NOS NÃO- LUGARES DA PÓS-MODERNIDADE}

Como destacamos anteriormente, alguns dos conceitos mais importantes em toda a história da antropologia encontram-se nos dias de hoje em profunda crise. A perda significativa de conteúdo que a categoria espaço experimenta é algo que pretendemos discutir mais demoradamente neste momento.
Para tanto, nos debruçaremos, agora, sobre as idéias desenvolvidas por AUGÉ (1994) sobre a surmodernité, em especial sobre suas reflexões a respeito da construção das identidades nos chamados não-lugares.

Para este pesquisador, esta sobremodernidade, que impõe novos problemas para a antropologia, é marcada pela figura do excesso, ou seja, pela potencialização de elementos próprios da era moderna, presentes desde o início do desenvolvimento da sociedade capitalista ocidental.

Esse excesso refere-se sobretudo a dois destes elementos, o tempo e o espaço, que estão na base do problema central discutido neste texto: a formação das identidades.

O tempo, como nenhuma outra categoria, atravessa hoje uma crise na sua capacidade inteligível, sobretudo em se tratando de sua utilização em pesquisas antropológicas.

A história acelerou-se de tal maneira que o foco de análise pós-moderno se concentra no presente, enquanto este é ainda passível de explicação. O passado nos escapa, não conseguimos atribuir sentido aos acontecimentos que tiveram curso em nosso passado recente, isto devido à superabundância da sobremodernidade. Augé define muito bem esta situação angustiante com a expressão "estamos com a história em nossos calcanhares", pensando nossa impotência diante de tal processo. (AUGÉ, 1994, p.30)

A segunda figura do excesso apontada por este autor é a que afeta o fator espaço. De maneira paradoxal, o mundo alargou-se e tornou-se mínimo ao mesmo tempo.

Através do desenvolvimento tecnológico, sobretudo dos transportes e das telecomunicações, tomamos conhecimento sobre a existência de lugares que antes nem imaginávamos que existissem. Nossos horizontes se expandiram de forma espantosa, saindo dos limites de nosso Estado-nação e partindo para uma esfera que se propõe global.

Concomitantemente, o mundo tornou-se tão pequeno que cabe na tela de nossos computadores pessoais, ou tão ínfimo que podemos cortá-lo de um pólo a outro em poucas horas a bordo de aeronaves que viajam a velocidades supersônicas.

Augé apresenta estas figuras de excesso para destacar que no mundo pós-moderno devemos rever, sobretudo enquanto pesquisadores, nossa concepção acerca do espaço, de forma a poder identificar os novos lugares, ou melhor, os não-lugares nos quais as identidades são produzidas atualmente.

Tal revisão deve obrigatoriamente passar pela crítica de um dos expedientes metodológicos mais tradicionais da antropologia: o conceito de lugar antropológico.

Esse lugar é entendido por Augé como uma construção concreta e simbólica que, apesar de estar longe de dar sentido para toda a vida social dos grupos, comporta um poder explicativo para todos os que o habitam. Os indivíduos que coabitam determinado lugar constroem sua cosmologia na sua interação com o meio. O local onde se dá a caça, onde se dorme, onde se reúnem, onde praticam seus rituais, é parte indispensável das identidades individuais e coletivas.

Assim como o lugar diz aos seus habitantes quem estes são, o antropólogo, para entender o outro, lança-se ao estudo de suas relações com este lugar. 
O autor aponta que, para serem de fato lugares antropológicos, estas construções devem possuir como principais características o fato de serem identitárias, relacionais e históricas. (idem, p.52-54)

Identitárias no sentido em que os indivíduos, através do nascimento, são inseridos em um determinado território ocupado por um determinado grupo, no qual o recém-nascido será automaticamente inserido, passando a seguir as regras sociais vigentes neste território.

O lugar é relacional na medida em que coloca elementos diversos em um mesmo local, obrigando-os a partilhar de um mesmo conjunto de códigos, através dos quais se vêem como iguais.

E, finalmente, o lugar é histórico, ou seja, goza de certa estabilidade durante o tempo. Neste lugar os indivíduos identificam monumentos, construções, objetos que são provas materiais de uma existência estável que transcende a efêmera existência individual e que, desta forma, fundam uma identidade cultural do grupo. (idem, p.58-60).

Entendendo lugar antropológico como construção que possui as características acima citadas, Augé atribui o nome de não-lugares às produções modernas que não possuem nada de identitário, de relacional ou de histórico.

A sobremodernidade como produtora de não-lugares não aboliu de forma alguma os lugares, porém, a cada dia que passa, estes passam a ser menos importantes na vida do homem contemporâneo. Os locais onde não se fincam raízes, onde não se travam relações sociais e onde o passado não existe e o presente é apenas algo transitório, é o habitat do homem pós-moderno. Os aeroportos, as cadeias de hotéis, as colônias de férias, as rodovias, as ferrovias, a rede internacional de computadores são alguns destes não-lugares que compõem a paisagem sobremoderna. (idem, p.71-82)

Estes não-lugares impõem aos indivíduos uma situação nova, de solidão, onde as relações sociais são definidas através de códigos, em sua grande maioria textos e contratos, que dispensam qualquer contato humano direto.

Quando viajamos em uma rodovia, não precisamos interagir com nenhum ser humano, à medida que as placas indicativas orientam o caminho e lembram as regras que ordenam aquele não-lugar.

O não-lugar também liberta os indivíduos das determinações particulares que são adquiridas ou formuladas nos lugares. Ao entrar em uma aeronave sou apenas um número e, como tal, estou livre de todo um complexo de características que me distingue dos outros seres humanos. Como escreve Augé, "o espaço do não-lugar não cria nem identidade singular nem relação, mas sim solidão e similitude". (idem p.95)

A grande contribuição deste autor, no que tange ao entendimento de como se formam as identidades em um contexto pós-moderno, está justamente na descoberta de que os novos lugares criados por este novo período histórico não são produtores de identidades, ao menos como nós as entendíamos. Qualquer análise que não dispense relativa atenção para a existência destes novos espaços corre o risco de estar fundamentando-se sobre bases incompletas. Lugares e nãolugares são esferas que devem ser interconectadas para que se possa captar o processo de construção das identidades culturais de uma forma satisfatória, pois se os primeiros as sedimentam, os segundos as desarticulam em momentos de intensa solidão e de perda de sentidos precisos.

\section{O MERCADO COMO DEFINIDOR DAS IDENTIDADES}

Verificaremos agora as implicações entre a crise no processo de construção das identidades e a esfera política da sociedade atual.

Que as instituições políticas tradicionais estão em crise não há como negar. O descrédito da grande maioria da população para com as esferas institucionais onde se dá o jogo político é algo detectado já há algumas décadas.

Entretanto, como escreve Néstor García Canclini, a instituição central que funda a modernidade, o Estado-nação, também dá mostras de sua fragilidade atual.

Este autor defende a idéia de que uma das marcas mais significativas desta conjuntura globalizada é o fato de que esta instituição maior já não serve como estrutura ou base para a articulação do conjunto de elementos que confere identidade ao grupo que habita em seu interior. $O$ local de construção destas identidades saltou da esfera política dominada pelo Estado para o interior do mercado global. (CANCLINI, 1997)

O caminho traçado por Canclini na investigação a respeito deste deslocamento negativo passa pela transformação de significado de um dos termos mais utilizados na teoria política moderna: cidadania.

Podemos definir cidadania, recorrendo à obra de ARENDT (1993), como o ato de falar e ser ouvido em um espaço público partilhado por iguais, sobre assuntos que dizem respeito à coletividade.

Esta participação em espaços coletivos é algo essencial para a construção das identidades nacionais. É através do diálogo político que os homens constroem as suas concepções acerca de quem são e quais as regras que devem pautar suas vidas em coletividade.

Esta identidade construída nos espaços de interlocução política deve ser entendida como sendo fruto de um processo que implica o reconhecimento das diferenças e dos direitos de todos os que participam. Dentre estes direitos, como destaca Lefort, o principal é o "direito a ter direitos", que se refere à dimensão simbólica da cidadania, um direito sempre reposto que passa a orientar as práticas políticas dos indivíduos. (LEFORT, 1987)

Entretanto, com a crise destes espaços públicos, ao menos os tradicionais (partidos, sindicatos, Poder Legislativo, Estado), o exercício de uma cidadania que conduza à construção de identidades culturais está abalada.

Cada vez mais estes espaços cedem lugar ao mercado, que através das mercadorias confere sentido à existência dos homens.

Como destaca TURCKE (1998), o desenvolvimento tecnológico em curso desde o início da era moderna destruiu todas as esferas de ordenamento social anteriores, tais como a família, a religião, a política, sem colocar em seu 
lugar algo que pudesse cumprir a mesma função. Esta lacuna, que atinge em cheio a cosmologia do homem moderno, que não consegue atribuir sentido à sua existência, é cada vez mais preenchida pelas mercadorias. $\mathrm{Na}$ desorientação de nossas vidas nos apegamos ao logotipo e à marca registrada da mercadoria, de modo a transferir sua carga de significado para nós, seres humanos desorientados.

Temos então que analisar a construção das identidades culturais no mundo pós-moderno voltando um olhar especial à forma como se organiza o seu mercado, já que este é um dos locais onde se constroem os elementos constituintes das identidades coletivas.

Canclini identifica uma desfiguração da oposição entre o alheio e o nosso, ou seja, não podemos ter uma clara visão acerca do que realmente é nosso ou do que foi produzido dentro de nosso território espacial. Isto porque os produtos não são produzidos em um única localidade. É cada vez mais natural que uma mercadoria seja formada por peças que são produzidas em países e continentes diferentes. (CANCLINI, 1997, p.16)

Distinguindo o processo de internacionalização, em curso há vários séculos, e a nova globalização, Canclini destaca que a especificidade da pós-modernidade está no fato de que não existe um centro desencadeador que sirva como referência absoluta na definição das mercadorias e das práticas culturais.

As identidades passam a ser construídas sob bases transterritoriais. O Estado já não serve como critério de definição, muito menos o partido e os espaços políticos tradicionais. Diante de um mercado mundializado, os valores culturais que sustentam as singularidades são produzidos como mercadorias através dos meios de comunicação de massa, não se filiando a nenhum território ou nação específica.

Entretanto, esta mercadoria definidora das identidades, por ser expressão da potencialização da lógica do modo de produção capitalista, traz em si a dcsigualdade. Nem todos podem ser consumidores desta cultura-mercadoria mundial, permanecendo apenas como espectadores de um show do qual não podem participar.

Cada vez mais o indivíduos são forçados a se adaptar dentro da tensão entre suas raízes culturais, que não foram de todo abolidas pelo mercado (uma vez que este é gerador de exclusão), e a cultura global tornada mercadoria de consumo.

\section{O FENÔMENO POLÍTICO DA AFIRMAÇÃO DAS IDENTIDADES CULTURAIS}

Como já foi possível detectar nos itens anteriores, o processo pós-moderno de construção de identidades culturais se dá no interior da tensão entre as esferas locais e globais. Desta tensão temos igualmente um movimento de homogeneização, como esta que o mercado opera, e também uma crescente formação de múltiplas identidades particulares.
Estes fenômenos, sem dúvida alguma, operam uma transformação ao nível das instituições políticas nos níveis nacionais. Nesta parte do texto discutiremos alguns dos novos problemas que as afirmações das identidades, antes minoritárias, trazem para a vida política do mundo contemporâneo.

As identidades na modernidade foram marcadas prioritariamente por duas figuras hegemônicas centrais: o indivíduo e o Estado.

Sousa Santos destaca que, com o triunfo do liberalismo como ideologia oficial do modo de produção capitalista, acabou-se por subordinar as identidades culturais dos povos ao poder supremo dos Estados nacionais e dos ideais individualistas. (SANTOS, 1993, p.34-35)

Esta opressão das identidades culturais foi operada com maestria quando da fundação dos Estados. Na medida em que necessitavam organizar um território que aspirasse à homogeneidade, as elites dominantes se valeram de recursos legais e opressores para forçar o abandono de práticas culturais particulares, para o bem da unidade nacional, construindo a figura artificial do povo nacional.

Entretanto, na pós-modernidade, como destacamos no item anterior, o Estado atravessa uma crise que abala esta posição hegemônica estabelecida no passado. Não podendo mais abarcar sob suas instituições oficiais os vários particularismos que compõem o conjunto da sociedade, o Estado vê surgir à sua frente uma multiplicidade de atores sociais que, dispersos, passam a reivindicar seus direitos.

Ocorre a constituição de múltiplos personagens políticos sem que estes se articulem incorporando um super-sujeito, tal como o Estado no período anterior.

Este fenômeno é entendido por Sousa Santos como fruto de uma crise de passagem de um modo de produção a outro. Vivemos há alguns anos uma crise do que convencionouse chamar de capitalismo organizado, onde os Estados tinham um papel essencial na realização da produção. Emerge em seu lugar algo que tem sido denominado de capitalismo desorganizado, que já não segue padrões de regulação e cujo controle não está nas mãos de ninguém, com níveis de exploração e exclusão nunca vistos. (idem, p.41-42)

Portanto, esta crise social evidenciada pela recontextualização das identidades culturais de uma forma dispersa e desarticulada se dá sem que seja realizada uma crítica da sociedade capitalista. Ao contrário, esta pulverização dos atores acaba por favorecer o aumento dos níveis de exclusão.

Isto se deve ao fato de que, em um panorama marcado pelas reivindicações de milhares de grupos particulares, diminuem as possibilidades de formulação de uma crítica e de um projeto político revolucionário que vise transformar a sociedade.

Faz-se necessário, nesta pós-modernidade, encontrar uma forma de coalisão entre os diversos atores através de uma reivindicação que, trazendo em seu interior uma crítica ao sistema, possa ser defendida por todos, organizados em movimentos sociais.

Igualmente problemático é o fenômeno contrário, detectado por Paula Montero, onde estes particularismos são transformados em instrumentos políticos na reivindicação 
de direitos, por meio da homogeneização forçada dos particularismos.

Tendo como estudo de caso a atuação do PT na administração da cidade de São Paulo, a autora demonstra que por trás de uma valorização política das minorias ocorre um processo paradoxal de redução das especificidades culturais. (MONTERO, 1996)

Analisando uma exposição organizada pela Secretaria de Cultura desse município, a autora verifica uma preocupação institucional em promover uma ação pedagógica que coloque a questão da cidadania e dos direitos das minorias como questão central na pós-modernidade.

Entretanto, o encaminhamento trilhado para alcançar este fim acaba por levar a um outro, extremamente perigoso para estas populações.

Tomando como primeiro exemplo as ações que visam demarcar os direitos dos povos indígenas, verificamos que a atitude inicial dos organizadores do movimento é elaborar um arquétipo do indivíduo indígena que possa servir como símbolo das populações envolvidas na questão. Entretanto, com isto opera-se uma homogeneização do que na realidade é extremamente diverso. Várias etnias são aglutinadas em torno da figura do índio, ficando subsumida a imensa diversidade cultural existente. (idem, p.111)

Isto pode acarretar uma perda crescente de identidade das comunidades que tão recentemente alcançaram relativa autonomia cultural e política.

Problema similar ocorre quando das campanhas políticas contra a exclusão social. Opera-se, aqui, uma redução ainda maior. Os vários atores políticos que compõem a sociedade nacional e que partilham de uma mesma situação de despossuídos de direitos básicos de cidadania são, de maneira homogênea, agrupados sob a categoria de excluídos. (idem, p.112)

Não se deve questionar a validade de tais manifestações em prol da inclusão destas populações marginalizadas. Entretanto, quando reduzimos a imensidão de perspectivas que cada ator político possui, reduzimos também a força do movimento.

Faz-se necessário repensar as figuras de vanguarda política no que se refere à sua operacionalidade em um contexto pós-moderno em que as minorias adquiriram voz. Talvez mais frutífero fosse deixar, neste momento, que os próprios atores falassem por si, tendo como instrumento de luta política a afirmação de sua identidade particular.

\section{IDENTIDADES SINCRÉTICAS}

Reservamos para esta etapa conclusiva do presente trabalho a apresentação de alguns dos pontos desenvolvidos por Massimo Canevacci acerca do contexto pós-moderno na construção das identidades culturais. Parece-nos que as idéias deste antropólogo podem dar uma noção de conjunto às partes dispersas apresentadas anteriormente.

Em seu trabalho Sincretismos: uma exploração das hibridações culturais, este autor mostra como, diante de um mundo transformado pelo desenvolvimento tecnológico, o $e u$ se forma, em uma situação em que o alheio e o familiar estão dissolvidos.

Recorrendo à origem da utilização do termo, o autor destaca que originalmente o sincretismo situava-se no campo da religião. No período de fundação das colônias periféricas, as metrópoles, com a finalidade de dominar os povos nativos por completo, lançaram mão de expedientes que pudessem promover a sua submissão espiritual. Freqüentemente os colonizadores incorporavam elementos da cultura nativa nas religiões oficiais para que os colonizados pudessem aceitá-las de uma forma mais pacífica.

Com o advento da era moderna e, de forma potencializada, na pós-modernidade, este sincretismo foi liberado da religião (uma vez que os crenças das minorias foram legalizadas e seu culto autorizado pelos Estados nacionais) e passou a manifestar-se no campo da cultura.

Este novo sincretismo aparece como uma troca simultânea de elementos culturais entre povos diferentes, isto sem que se identifiquem centros geradores ou periferias receptoras, passando a valer o "princípio de que muitas periferias estão no centro, e de que muitos centros estão na periferia". (CANEVACCI, 1996, p.21)

Esta troca é marcada basicamente pela contradição da coexistência do incompatível, onde um traço cultural potencialmente estranho ao receptor passa a ser aceito e, em alguns casos, até mesmo desejado. Este fenômeno é entendido por este autor como o fruto de uma mudança na paisagem mundial, onde os fenômenos não podem mais ser divididos entre locais e globais. O termo que deve guiar uma nova antropologia que se presta ao estudo destas novas mutações culturais deve adotar a dimensão glocal como princípio explicativo. Neste conceito, o local e o global se fundem como instâncias de uma mesma realidade significativamente nova. (idem, p.23-25)

Nesta nova paisagem ocorre uma verdadeira desordem nos referenciais que anteriormente serviam como definidoros do eu. Os indivíduos perdem a capacidade de orientar-se em um mundo que deixou de ser sua casa.

O processo de identificação cultural passa a se processar sob a desorientação de uma dialética sincrética. Para entender tal termo convém retomar o sentido da palavra dialética. Formulada pela filosofia idealista alemã, esta palavra referese ao processo onde uma tese é posta em colapso por uma antítese, gerando uma situação de crise, até o momento em que a ordem é novamente estabelecida pela síntese.

A dialética sincrética subverte este conceito. Igualmente partindo da relação conflituosa entre a tese e a antítese, o sincretismo nega a síntese, permanecendo ambíguo. As identidades, nesta nova dialética, não são mais a síntese de uma relação entre duas culturas, mas, sim, a desordem de ser um duplo eu. Na realidade, um nós. (idem, p.39)

Uma tentativa de expressar sumariamente esta situação sincrética proposta por Canevacci é através da paradoxal afirmação do $e u$ de uma unidade. As identidades culturais devem ser entendidas na pós-modernidade como um constructo plural, onde não existem elementos dominantes e subalternos, locais e estrangeiros. O que impera nas identidades desta nova paisagem é a polifonia sincrética que não obedece a critérios previamente definidos. 
Diante de tal mosaico, só podemos ter uma certeza: as ciências sociais, em especial a antropologia, necessitam reformular seus pontos de vista, para melhor visualizar uma realidade transformada. Trata-se de encontrar um novo posicionamento sobre fenômenos que acontecem já há algum tempo, porém, que adquiriram uma força avassaladora nas últimas décadas. Os pontos apresentados aqui levantam apenas alguns dos principais problemas envolvendo a complexa condição humana no mundo contemporâneo.

\section{REFERÊNCIAS BIBLIOGRÁFICAS}

ARENDT, Hannah. A condição humana. São Paulo: Forense, 1993.

AUGÉ, Marc. Não-lugares. Introdução a uma antropologia da supermodernidade. São Paulo: Papirus, 1994.

"Agora somos todos contemporâneos". Sexta Feira, n.3, p.112119, out. 1998. Entrevista concedida a Paula Miraglia.

CANCLINI, Néstor García. "Consumidores do século XXI, cidadãos do século XVIIl". In: Consumidores e cidadãos: conflitos multiculturais da globalização. Rio de Janeiro: Ed. UFRJ, 1997.

CANEVACCI, Massimo. Sincretismos: uma exploração das hibridações culturais. São Paulo: Studio Nobel/Instituto Cultural Ítalo Brasileiro/ Istituto Italiano di Cultura, 1996.

LEFORT, Claude. "Direitos do homem e política". In: A invenção democrática, os limites do totalitarismo. São Paulo: Brasiliense, 1987.

MARCUS, George. "Identidades passadas, presentes e emergentes: requisitos para etnografias sobre a modernidade no final do século $\mathrm{XX}$ ao nível mundial". Revista de Antropologia, v.34, p.197-221, 1991.

MARX, Karl. O capital. livro 1. v.1. Rio de Janeiro: Bertrand Brasil, 1991.

MONTERO, Paula. "Reflexões sobre uma antropologia das sociedades complexas". Revista de Antropologia, v.34, p.103-130, 1991.

"Cultura e democracia no processo da globalização". Novos Estudos Cebrap, n.44, p.89-114, mar. 1996.

SANTOS, Boaventura de $S$. "Modernidade, identidade e a cultura de fronteira". Tempo Social - Revista de Sociolgia da USP, v.5, n.1-2, p.3152, nov. 1994.

TURCKE, Christoph. "A luta pelo logotipo". (Transcrição de palestra proferida na Universidade Federal de Santa Catarina em agosto de 1998)

WEBER, Max. A ética protestante e o espírito do capitalismo. São Paulo: Pioneira, 1996. 